\title{
Association of Cardiac Development with Assisted Reproductive Technology in Childhood: A Prospective Single-Blind Pilot Study
}

\author{
Jie Zhou ${ }^{a}$ Hong Liu ${ }^{b}$ Hai-tao Guc Yu-gui Cuid Nan-nan Zhao ${ }^{d}$ Juan Chen ${ }^{d}$ \\ Li Gao $^{d}$ Yuan Zhang ${ }^{d}$ Jia-yin Liu ${ }^{d}$ \\ aThe Department of Echocardiography, ${ }^{b}$ Department of Cardiothoracic Surgery, 'Department of \\ Pediatric Cardiology, dState Key Laboratory of Reproductive Medicine, Clinical Center of Reproductive \\ Medicine; First Affiliated Hospital of Nanjing Medical University, Nanjing, China
}

\section{Key Words}

Assisted reproductive technologies $\bullet$ Echocardiography $\bullet$ Cardiology $\bullet$ Pediatrics

\begin{abstract}
Aims: To examine the pattern and extent of cardiovascular developmental alterations among children conceived by assisted reproductive technology (ART) and its association with potential confounders. Methods: The present study was a prospective single-blind pilot design lasting 15 months. The ART group was recruited by a non-random, consecutive sample on the basis of the unique personal identification number assigned to ART children, whereas spontaneous conception controls were recruited by a population-based random sample from the same hospital by age. Echocardiography was available for the measurement of 128 ART children and 100 controls with respect to cardiovascular geometric morphology and cardiac function. Results: The majority of cardiac geometric morphology parameters were comparable among the study groups $(P>0.05)$, except for significant increases in left ventricular (LV) relative wall thickness $(P=0.038)$, LV mass index $(P=0.005)$ and LV remodeling index $(P=0.005)$ in ART children after adjustment for age, gender, body surface area and heart rate. The results showed similarity in LV systolic function characterized by ejection fraction $(P=0.140)$ and shortening fraction $(P=0.167)$ between the groups. However, ART children had a significant tendency toward a decrease in mitral $\mathrm{A}(P=0.008)$ and mitral $\mathrm{E}^{\prime}(P=0.012)$ compared with controls after adjusting for confounders. Additionally, Cox analysis suggested an independent association $(P<0.05)$ of anthropometrics and perinatal outcomes in addition to the ART procedure itself with the differences in cardiac developmental status. Conclusion: Our findings support the presence of remodeling in the left cardiac geometric morphology and diastolic dysfunction and the absence of any change to the aortocoronary morphometry or systolic function in ART children compared with controls, which may be independently associated with the anthropometrics and perinatal outcomes in addition to the ART procedure.
\end{abstract}

Dr. H Liu and J Zhou contributed equally to this work. 


\section{Introduction}

Since 1978, when the world's first "test tube baby" was born [1], assisted reproductive technology (ART) has extensively allowed for pregnancy in cases of infertile couples, and over five million babies worldwide have been conceived by ART [2], with a reported prevalence ranging from $3.5 \%$ to $16.7 \%$ in developed countries and from $6.9 \%$ to $9.3 \%$ in developing countries [3].

While ART is generally considered favorably [4], a considerable number of studies have already suggested the potential association between ART and an increased risk for adverse perinatal outcomes and congenital malformations [5-7], in part due to the changes in the choreography of fertilization compared with spontaneously conceived controls [8,9], which may give rise to the long-term consequences for the developmental origins of health and disease, as well as growth [10-12].

In addition to neuropsychological development [13-15], concern has been voiced regarding the cardiovascular developmental status of children conceived by ART [16]. Growing evidence has indicated the likely presence of systemic and pulmonary vascular dysfunction $[17,18]$, as well as elevated blood pressure during childhood and adolescence, among individuals conceived by ART [19]. The latest study supports a possible association between ART and cardiovascular remodeling in the fetal and postnatal periods [20]. Advanced parental age has been suggested to be related to the increased risk of postnatal adverse outcomes [21, 22]; however, it has also been suggested that the underlying pathology of infertility and exposure to ART increase the embryogenic susceptibility to a spectrum of cardiovascular developmental dysfunctions in infancy and childhood. Of particular concern among the potential long-term consequences of ART is cardiac health, but very few studies to date have focused on the possible impact of ART on cardiac geometric morphological and hemodynamic development, which is required to expand our knowledge of the subsequent impact of ART on cardiovascular function and on the design of preventive strategies [20].

On the basis of the hypothesis that at least one of the parental predisposing infertility factors or the ART procedure itself is likely to lead to the poorer cardiovascular developmental status and higher prevalence of cardiovascular abnormalities than spontaneous conception controls, we designed a prospective single-blind pilot study to examine the pattern and extent of cardiovascular developmental adaptations in children conceived by ART, as well as its association with potential confounders.

\section{Materials and Methods}

\section{Study design}

A historic cohort study was designed with prospective follow-up of ART children born in the Clinical Center of Reproductive Medicine (CCRM) of First Affiliated Hospital of Nanjing Medical University (FAHNMU) from 1 January 2002 to 31 December 2012. The present study was a prospective design during 15 months (1 September 2012 through 31 March 2014) in CCRM. The ART group was recruited by a nonrandom, consecutive sample on the basis of the unique personal identification number assigned to ART children born in CCRM, whereas the spontaneously conceived controls were selected by age as a populationbased random sample from the same hospital. This study specifically focused on the cardiac development of children conceived by ART, and the possible associations with parental infertility and the ART procedure used were determined as well. Figure 1 shows a flow diagram of the study population.

\section{Blinding}

A sophisticated sonographer blinded with regard to the mode of conception as well as the the baseline data of all participants was involved in the entire process of echocardiographic measurement to avoid intraobserver bias. The demographics, anthropometrics, perinatal outcomes and ART characteristics of the ART participants were independently collected by a review of medical records in CCRM, and those of the controls were collected by parental questionnaires and real-time measurements, if feasible. 
Zhou et al.: Cardiac Development in Assisted Reproductive Techniques

Fig. 1. Flow diagram of the study populations. ART indicates pregnancies conceived by assisted reproductive technologies; Echo is an abbreviation for echocardiography.

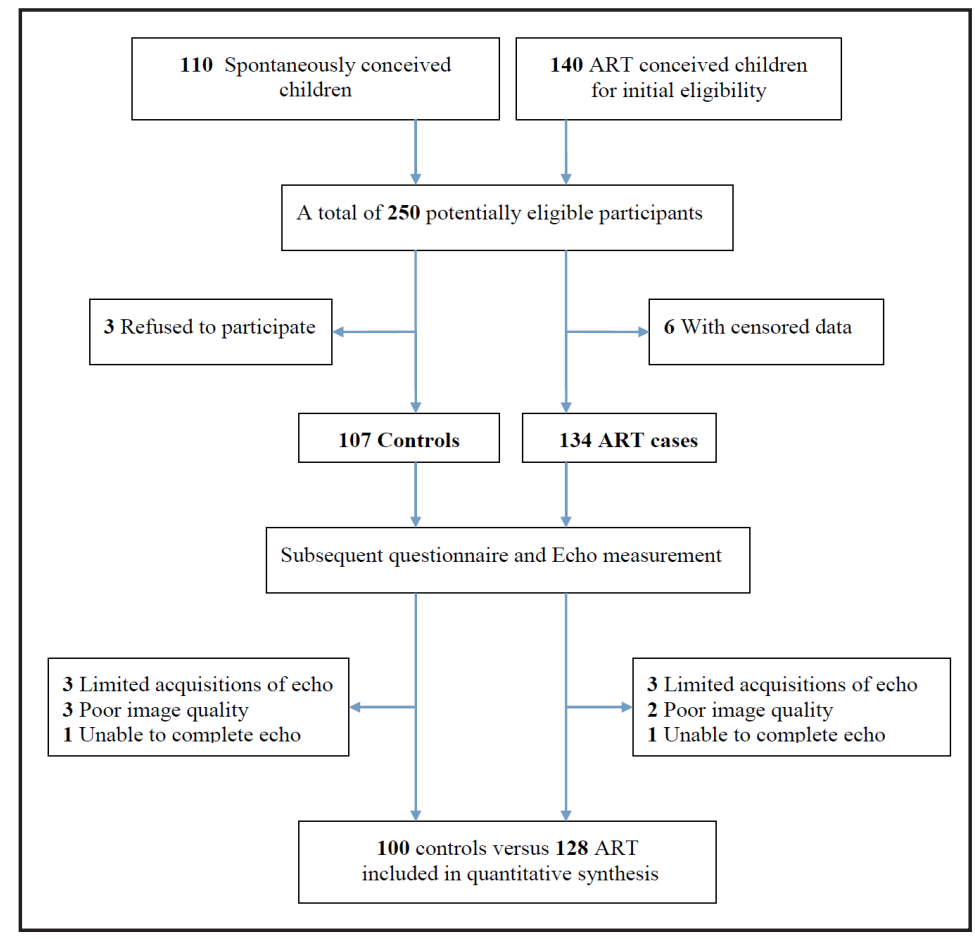

\section{Ethics information}

The implementation of this study protocol was in accordance with the Declaration of Helsinki and was approved by the Institutional Ethics Committee (IEC) of FAHNMU (20120-SR-048). FAHNMU is qualified and registered with the Association for the Accreditation of Human Research Protection Program (AAHRPP). Written parental informed consent was obtained for all study participants.

\section{Inclusion and exclusion criteria}

The inclusion criteria included the capability to perform a complete transthoracic echocardiography examination, as well as the absence of any complex cardiac malformations or systemic diseases. Conversely, the exclusion criteria included a history of cardiovascular or systemic diseases, frequent arrhythmias, critical acquired heart diseases, a familial history of cardiomyopathy, and any limitation to the acquisition of echocardiographic imaging or poor image quality available for assessment.

\section{Measurement and instrument protocol}

In adherence to the Task Force Recommendations [23, 24], the transthoracic echocardiography was performed for data collection regarding cardiovascular morphometrics and hemodynamics, which was subsequently used for cardiac assessments following the standardized protocols $[25,26]$. Of particular note was the extension of the As Low As Reasonably Achievable (ALARA) principle concerning acoustic exposures during the echocardiographic examinations in case of potential hazards [27, 28]. The diagnostic criteria for cardiac malformations were coded using the WHO International Classification of Diseases, $10^{\text {th }}$ Revision (ICD-10).

A commercial ultrasound machine (No. YZB/USA2489-2011, iE33, Philips Ultrasound Inc., Bothell, USA) was available for echocardiographic examinations using ergonomic XMATRIX transducers with 1-8 MHz 2D phased array probes (S8-3 or S5-1) designed for children. Four consecutive cardiac cycles at a frame rate of 80-100 were acquired for cardiac assessments of all participants.

\section{Measurement for cardiovascular geometric morphology}

The left ventricular end-diastolic diameters (LVDD) and end-systolic diameters (LVSD) were measured by M-mode echocardiography at the para-sternal long-axis views. The LV end-diastolic volume (LVEDV) and end-systolic volume (LVESV) were calculated by 2D echocardiography from the apical four-chamber view using the modified Simpson's rule. Aortic diameters (AOD) and left atrial diameters (LAD) were measured 
using 2D echocardiography at the para-sternal long-axis views. The left and right coronary arteries were measured using 2D echocardiography at the short-axis views. The interventricular septum thickness (IVST) and the left ventricular posterior wall thickness (LVPWT) were measured by M mode from a para-sternal long-axis view. Left ventricular relative wall thickness (LVRWT) was calculated the following equation: (IVST+PWT)/ LVDD. The left ventricular remodeling index (LVRI) was calculated as follows: LV mass / LVEDV. LV mass was calculated using Devereux's formula [29], and the LV mass index (LVMI) was normalized by body surface area (BSA) and modified according to anthropometric data of the Chinese population [30]. All echocardiographic measurements were based on the average of four consecutive cardiac cycles.

\section{Measurement of cardiac function}

The LV shortening fraction was calculated from the internal ventricular diameters obtained on a para-sternal long-axis view in the M mode using the following equation: (end-diastolic diameter-endsystolic diameter)/end-diastolic diameter. $\mathrm{LV}$ stroke volumes were calculated as follows: $\pi / 4 \times$ (aortic valve diameter) ${ }^{2} \times$ (aortic artery systolic flow velocity-time integral). The left ejection fraction was calculated as follows: (end-diastolic volume-end-systolic volume)/end-diastolic volume. The left cardiac outputs were calculated as stroke volume $\mathrm{x}$ heart rate. The left cardiac indices were normalized as cardiac outputs/ BSA.

The mitral inflow velocities, including the peak velocities during early diastole (E) and late diastole (A), were measured using pulsed-wave (PW) Doppler in the apical four-chamber view by performing continuous-wave (CW) Doppler prior to applying the PW Doppler to allow the maximal velocities. The mitral annular velocities, including the early diastolic $\left(E^{\prime}\right)$ and late diastolic $\left(A^{\prime}\right)$ velocities, were measured from tissue Doppler imaging (TDI) in the apical views at end-expiration to assess LV filling. In addition, the $\mathrm{E} / \mathrm{A}$ ratio, the $\mathrm{E}^{\prime} / \mathrm{A}^{\prime}$ ratio, and the $\mathrm{E} / \mathrm{E}^{\prime}$ ratio were recalculated as predictors in the estimation of $\mathrm{LV}$ filling pressures. The pseudo-normal pattern could be distinguished from the true normal pattern by pre-load reduction during the Valsalva maneuver [31].

\section{Sample size and power analysis}

Considering the high sensitivity for preclinical cardiac dysfunction, annular peak velocities measured by TDI were chosen to calculate the sample size. On the basis of previous studies measuring cardiac function $[20,24]$, the sample size was calculated to allow observation of a difference of $25 \%$ in mitral $E^{\prime}$ values for ART children. For a power of $80 \%$ and an $\alpha$ risk of 0.05 , a minimum of 91 subjects per study group was required. We preliminarily recruited 140 children conceived by ART and 110 conceived naturally in case of the limited power.

\section{Statistical analysis}

The results were presented as mean values \pm standard deviations (SD) for continuous data and as percentages for categorical data. The normality test for all of the continuous variables was performed using the Kolmogorov-Smirnov test. Continuous data were compared by Student's t test or one-way ANOVA, categorical data by the $\chi 2$ test or the Fisher's exact test, and ordinal data by Wilcoxon's rank-sum test or Kruskal-Wallis's rank-sum test, when appropriate. Univariate regression analysis was performed for the determination of contributing predictors associated with cardiac developmental status by a log-rank test or linear regression analysis, if available. The significant covariates with $p$ values less than 0.10 in univariate analyses were then considered for subsequent multivariate analyses to allow the determination of independent predictors associated with cardiac developmental status, using Cox proportional hazards regression models by the method of forward likelihood ratio (LR). A $p$ value less than 0.05 was considered statistically significant with a 2-tailed test. Statistical analyses were completed in SPSS version 16.0 for windows (SPSS Inc., Chicago, Illinois, USA).

\section{Results}

Baseline and perinatal characteristics

A total of 228 patients met the inclusion criteria (128 for ART versus 100 for controls). In terms of baseline anthropometrics, age, gender, height, weight, heart rate, BSA and body mass index (BMI), the characteristics were comparable between the ART 
Zhou et al.: Cardiac Development in Assisted Reproductive Techniques

Table 1. Baseline characteristics of the study groups. ART indicates pregnancy conceived by assisted reproductive technologies; †Adverse defined by the presence of bronchopulmonary dysplasia, necrotizing enterocolitis, intraventricular hemorrhage, periventricular leukomalacia, retinopathy, persistent ductus arteriosus, or sepsis. ${ }^{*} P$ value was calculated by Student's t test, Pearson's $\chi^{2}$ test or the Wilcoxon rank sum test when appropriate

\begin{tabular}{|c|c|c|c|}
\hline Variables & ART (128) & Control (100) & $P^{*}$ value \\
\hline \multicolumn{4}{|l|}{ Baseline Characteristics } \\
\hline \multicolumn{4}{|l|}{ Gender } \\
\hline Female & 57 & 41 & \\
\hline Male & 72 & 59 & 0.593 \\
\hline Age, month & $49.67 \pm 23.83$ & $47.15 \pm 26.70$ & 0.464 \\
\hline Height, $\mathrm{cm}$ & $106.37 \pm 15.50$ & $104.31 \pm 19.57$ & 0.375 \\
\hline Weight, Kg & $18.64 \pm 6.85$ & $177.74 \pm 9.12$ & 0.396 \\
\hline Heart rate, bmp & $98.5 \pm 15.6$ & $101.2 \pm 15.4$ & 0.200 \\
\hline Body mass index, Kg/m2 & $16.0 \pm 2.3$ & $15.9 \pm 3.8$ & 0.877 \\
\hline Body surface area, m2 & $0.73 \pm 0.18$ & $0.71 \pm 0.23$ & 0.447 \\
\hline \multicolumn{4}{|l|}{ Perinatal Characteristics } \\
\hline \multicolumn{4}{|l|}{ Pregnancy } \\
\hline Singleton & 91 & 94 & \\
\hline Twin & 37 & 6 & $<0.001$ \\
\hline \multicolumn{4}{|l|}{ Delivery } \\
\hline Cesarean & 100 & 50 & \\
\hline Spontaneous & 28 & 50 & $<0.001$ \\
\hline \multicolumn{4}{|l|}{ Neonatal outcome } \\
\hline Normal & 116 & 100 & \\
\hline Adverse $\dagger$ & 12 & 10 & 0.522 \\
\hline \multicolumn{4}{|l|}{ Apgar score } \\
\hline At $1 \mathrm{~min}$ & $9.85 \pm 0.50$ & $9.96 \pm 0.20$ & 0.043 \\
\hline At $5 \mathrm{~min}$ & $9.92 \pm 0.32$ & $9.98 \pm 0.14$ & 0.094 \\
\hline \multicolumn{4}{|l|}{ Amniotic fluid } \\
\hline Clarity & 121 & 94 & \\
\hline I turbidity & 5 & 4 & \\
\hline II turbidity & 1 & 2 & \\
\hline III turbidity & 1 & 0 & 0.864 \\
\hline Birth weight, g & $3188.3 \pm 625.1$ & $3387.0 \pm 489.3$ & 0.010 \\
\hline Gestational age at delivery, wk & $37.9 \pm 2.1$ & $39.3 \pm 1.4$ & $<0.001$ \\
\hline Cardiac malformations, $\%$ & $10.2(13 / 128)$ & $6.0(6 / 100)$ & 0.260 \\
\hline
\end{tabular}

and control groups, as shown in Table 1. Considering perinatal characteristics, the ART group had a higher occurrence of cardiac malformations and neonatal complications, but the difference failed to achieve statistical significance. Within the ART group, there were 9 patent foramen ovale (PFO: ICD10-Q21.103) with a diameter of $2.20 \pm 0.50 \mathrm{~mm}, 2$ atrial septal defects (ASD: ICD10-Q21.102) of $9.84 \pm 3.46 \mathrm{~mm}, 1$ ventricular septal defect (VSD: ICD10-Q21.001) of $7.30 \mathrm{~mm}$, and 1 aortopulmonary septal defect (APSD: ICD10-Q21.452) of $8.50 \mathrm{~mm}$. Within the control group, there were 5 PFO (ICD10-Q21.103) of $2.15 \pm 0.48 \mathrm{~mm}$ and 1 patent ductus arteriosus (PDA: ICD10-Q25.051) of $8.60 \mathrm{~mm}$. In addition, the ART group had an earlier gestational age at delivery, lower birth weights, and a higher occurrences of twins and cesarean deliveries in comparison with the controls. With regard to Apgar scores, the 1-min score of the ART neonates was inferior to that of the controls, while the 5-min score was similar between the groups.

\section{Subgroup analysis of baseline ART characteristics}

According to the mode of conception, ART was classified as in-vitro fertilization (IVF), intracytoplasmic sperm injection (ICSI), IVF+ICSI or artificial insemination (AI), as shown in Table 2. Significant differences among the subgroups were identified by considering the cause of infertility. As affected by infertility cause, the mode of sperm acquisition significantly differed across different subgroups. With respect to hormonal stimulation of ovulation and gamete source, no evidence of significant differences existed among the subgroups. Moreover, 
Zhou et al.: Cardiac Development in Assisted Reproductive Techniques

Table 2. Baseline characteristics of the assisted reproductive technology group. IVF, in-vitro fertilization; ICSI, intracytoplasmic sperm injection; AI, artificial insemination; FTET, frozen-thawed embryo transfer; COS, controlled ovarian simulation. NA, not applicable. ${ }^{*} P$ value was calculated by the one-way ANOVA or Fisher's Exact Test when appropriate. $\dagger$ Fisher's Exact Test was available for multiple comparisons among the subgroups except AI

\begin{tabular}{|c|c|c|c|c|c|}
\hline Covariates & $\begin{array}{l}\text { IVF } \\
(86)\end{array}$ & $\begin{array}{l}\text { ICSI } \\
(24)\end{array}$ & $\begin{array}{c}\text { IVF+ICSI } \\
(7)\end{array}$ & $\begin{array}{c}\text { AI } \\
(12)\end{array}$ & $P$ value* \\
\hline \multicolumn{6}{|l|}{ Etiological infertility cause } \\
\hline Primary & 51 & 20 & 6 & 10 & \\
\hline Secondary & 35 & 4 & 1 & 1 & 0.027 \\
\hline \multicolumn{6}{|l|}{ Parental infertility cause } \\
\hline Unexplained & 4 & 0 & 1 & 1 & \\
\hline Female & 52 & 1 & 2 & 6 & \\
\hline Male & 17 & 14 & 2 & 2 & \\
\hline Female+male & 13 & 9 & 2 & 2 & $<0.001$ \\
\hline \multicolumn{6}{|l|}{ Sperm acquisition mode } \\
\hline Ejaculated extracted sperm & 84 & 16 & 6 & 11 & \\
\hline Surgically extracted sperm & 2 & 8 & 1 & 0 & $<0.001$ \\
\hline \multicolumn{6}{|l|}{ Sperm source } \\
\hline Husband & 84 & 23 & 7 & 11 & \\
\hline Donor & 2 & 1 & 0 & 0 & 0.700 \\
\hline \multicolumn{6}{|l|}{ Oocyte source } \\
\hline Wife & 85 & 24 & 7 & 11 & \\
\hline Donor & 1 & 0 & 0 & 0 & 1.000 \\
\hline \multicolumn{6}{|l|}{ Ovulation control } \\
\hline Natural ovulation & 6 & 5 & 2 & 2 & \\
\hline $\cos$ & 49 & 16 & 4 & 5 & \\
\hline Mini-stimulation & 4 & 0 & 0 & 0 & \\
\hline Ovulation induction $+\operatorname{COS}$ & 27 & 5 & 1 & 4 & 0.515 \\
\hline \multicolumn{6}{|l|}{ Embryo transfer modality } \\
\hline Fresh embryo transfer & 67 & 16 & 4 & $\mathrm{NA}$ & \\
\hline Natural cycle FTET & 10 & 7 & 1 & NA & \\
\hline Hormone-replacement cycle FTET & 9 & 1 & 2 & NA & $0.099 \dagger$ \\
\hline \multicolumn{6}{|l|}{ Embryo transfer stage } \\
\hline Cleavage & 76 & 17 & 6 & NA & \\
\hline Blastocyst & 10 & 7 & 1 & $\mathrm{NA}$ & $0.094 \dagger$ \\
\hline Transferred embryos, $n$ & $2.22 \pm 0.80$ & $2.00 \pm 0.51$ & $2.00 \pm 0.58$ & NA & 0.440 \\
\hline
\end{tabular}

the differences were statistically insignificant regarding embryo transfer modality, stage and number among the subgroups other than AI.

\section{Baseline cardiovascular characteristics}

Both systolic and diastolic blood pressures were similar between the ART and control groups, as shown in Table 3. The majority of cardiac parameters examined by geometric morphology were comparable among the study groups, except for a significant increase in IVST, LVPWT, RWT, LVMI and LVRI within the ART group, even after adjustment for age, gender, body surface area and heart rate. As desired, the findings suggested the similarity of left systolic function and aortocoronary morphometry among the groups, irrespective of adjustment for confounders. Concerning cardiac diastolic function, although mitral E, mitral $\mathrm{A}^{\prime}$ and the mitral $\mathrm{E}^{\prime} / \mathrm{A}^{\prime}$ ratio were similar between groups, the ART children had a tendency toward decreases in mitral A and mitral $\mathrm{E}^{\prime}$, as well as toward increases in mitral E/A and mitral E/E' ratios compared with controls, among which the tendency remained significant after adjustment for multiple confounders.

\section{Univariate and multivariate analysis of independent predictors}

On the basis of the aforementioned differences between the ART and control groups, univariate analysis was used to determine contributing predictors from a series of confounders illustrated in Table 4. Cox proportional hazard analysis suggested that age was an independent predictor for cardiac geometric morphology and diastolic function. Heart 
Table 3. Baseline cardiovascular characteristics of the study groups. ART indicates pregnancy conceived by assisted reproductive technologies; LVDD, left ventricular diastolic diameter; LVSD, left ventricular systolic diameter; IVST, interventricular septum thickness; LVPWT, left ventricular posterior wall thickness; LVRWT, left ventricular relative wall thickness; LVEDV, left ventricular end-diastolic volume; LVESV, left ventricular end systolic volume; LVMI, left ventricular mass index; LVRI, left ventricular remodeling index; LCA, left coronary artery; RCA, right coronary artery, AOD, aortic diameter; E, ventricular inflow in early diastole; A, ventricular inflow during atrial contraction; $E^{\prime}$, annular peak velocity in early diastole, $\mathrm{A}^{\prime}$, annular peak velocity during atrial contraction. ${ }^{*} P$ value calculated by linear regression adjusted for age, gender, body surface area and heart rate

\begin{tabular}{|c|c|c|c|c|}
\hline Covariates & ART (128) & Control (100) & Crude $P$ value & Adjusted $P^{*}$ va \\
\hline \multicolumn{5}{|l|}{ Blood pressure, $\mathrm{mmHg}$} \\
\hline Systolic blood pressure & $100.9 \pm 10.9$ & $99.1 \pm 8.7$ & 0.173 & 0.196 \\
\hline Diastolic blood pressure & $60.9 \pm 9.5$ & $60.9 \pm 7.6$ & 0.952 & 0.786 \\
\hline \multicolumn{5}{|l|}{ Geometric morphology } \\
\hline Left atria, mm & $17.05 \pm 2.80$ & $16.91 \pm 2.99$ & 0.722 & 0.937 \\
\hline LVDD, mm & $33.75 \pm 4.15$ & $32.83 \pm 4.93$ & 0.129 & 0.210 \\
\hline LVSD, mm & $21.16 \pm 3.11$ & $20.42 \pm 3.32$ & 0.084 & 0.147 \\
\hline IVST, mm & $5.52 \pm 1.07$ & $5.12 \pm 0.82$ & 0.020 & 0.002 \\
\hline LVPWT, mm & $4.74 \pm 0.87$ & $4.37 \pm 0.69$ & 0.010 & 0.001 \\
\hline LVRWT & $0.310 \pm 0.060$ & $0.29 \pm 0.050$ & 0.067 & 0.038 \\
\hline LVESV, ml & $15.26 \pm 5.55$ & $17.03 \pm 5.07$ & 0.122 & 0.213 \\
\hline LVEDV, ml & $47.71 \pm 14.73$ & $45.16 \pm 16.97$ & 0.219 & 0.404 \\
\hline LVMI, $\mathrm{g} / \mathrm{m}^{2}$ & $55.70 \pm 15.14$ & $49.73 \pm 9.78$ & 0.001 & 0.005 \\
\hline LVRI, g/ml & $0.86 \pm 0.20$ & $0.80 \pm 0.14$ & 0.006 & 0.005 \\
\hline \multicolumn{5}{|l|}{ Aortocoronary morphometry } \\
\hline LCA, mm & $2.73 \pm 0.35$ & $2.68 \pm 0.48$ & 0.380 & 0.754 \\
\hline $\mathrm{RCA}, \mathrm{mm}$ & $2.38 \pm 0.31$ & $2.36 \pm 0.37$ & 0.650 & 0.767 \\
\hline $\mathrm{AOD}, \mathrm{mm}$ & $14.62 \pm 1.98$ & $14.45 \pm 1.91$ & 0.495 & 0.912 \\
\hline LCA/AOD ratio & $0.188 \pm 0.020$ & $0.186 \pm 0.028$ & 0.682 & 0.775 \\
\hline RCA/AOD ratio & $0.164 \pm 0.018$ & $0.164 \pm 0.024$ & 0.836 & 0.730 \\
\hline \multicolumn{5}{|l|}{ Left Systolic function } \\
\hline stroke volume, $\mathrm{ml}$ & $32.45 \pm 9.97$ & $31.09 \pm 11.59$ & 0.342 & 0.677 \\
\hline cardiac output, mL/min & $3.15 \pm 0.95$ & $3.05 \pm 0.93$ & 0.392 & 0.294 \\
\hline cardiac index, $\mathrm{L} / \mathrm{min} / \mathrm{m}^{2}$ & $4.41 \pm 1.34$ & $4.34 \pm 0.88$ & 0.696 & 0.210 \\
\hline shortening fraction, $\%$ & $36.90 \pm 4.62$ & $37.74 \pm 3.56($ & 0.136 & 0.140 \\
\hline ejection fraction, $\%$ & $68.03 \pm 4.77$ & $69.04 \pm 4.30$ & 0.100 & 0.167 \\
\hline \multicolumn{5}{|l|}{ Cardiac Diastolic function } \\
\hline Mitral E, mm/s & $97.70 \pm 18.01$ & $97.09 \pm 15.46$ & 0.790 & 0.648 \\
\hline Mitral A, mm/s & $59.51 \pm 14.91$ & $65.56 \pm 15.75$ & 0.003 & 0.008 \\
\hline Mitral E/A ratio & $1.72 \pm 0.46$ & $1.56 \pm 0.46$ & 0.010 & 0.015 \\
\hline Mitral $\mathrm{E}^{\prime}, \mathrm{mm} / \mathrm{s}$ & $9.66 \pm 1.52$ & $10.13 \pm 1.76$ & 0.030 & 0.012 \\
\hline Mitral $\mathrm{A}^{\prime}, \mathrm{mm} / \mathrm{s}$ & $6.24 \pm 1.58$ & $6.26 \pm 1.49$ & 0.892 & 0.940 \\
\hline Mitral $E^{\prime} / A^{\prime}$ ratio & $1.63 \pm 0.46$ & $1.71 \pm 0.52$ & 0.183 & 0.075 \\
\hline Mitral E/E' ratio & $10.36 \pm 2.59$ & $9.74 \pm 1.73$ & 0.038 & 0.014 \\
\hline
\end{tabular}

rate, BMI and BSA were independent predictors for geometric morphology, as shown in Table 5. Among the perinatal covariates, neonatal outcome and birth weight were independent predictors for geometric morphology, whereas delivery was independently associated with diastolic function. Embryo transfer stage was an independent predictor for geometric morphology, while the number of embryos transferred was a predictor for diastolic function. The association between hormonal stimulation and geometric morphology was statistically independent as well.

\section{Discussion}

This study demonstrates the presence of remolding in the left cardiac geometric morphology and diastolic dysfunction but the absence of adaption in the aortocoronary morphometry or systolic function among children of pregnancies obtained by ART. In addition, our findings suggested a potential association among the anthropometrics of participants (i.e., age, heart rate, BMI and BSA), perinatal outcomes (i.e., delivery, birth weight, and neonatal complications), and the ART procedure itself (i.e., hormonal stimulation of ovulation and stage and number of embryos transferred) as independent predictors for the differences in cardiac developmental statuses between ART and control children. 
Table 4. Univariate analysis of contributing predictors in terms of differences between ART and controls. ART indicates pregnancy conceived by assisted reproductive technologies; IVST, interventricular septum thickness; LVPWT, left ventricular posterior wall thickness; LVMI, left ventricular mass index; LVRI, left Ventricular Remodeling Index; A, ventricular inflow during atrial contraction; $E^{\prime}$, annular peak velocity in early diastole; NC, Natural conception; IVF, in-vitro fertilization; ICSI, intracytoplasmic sperm injection; AI, artificial insemination; COS, controlled ovarian simulation; MS, mini-stimulation; OI, ovulation induction; FET, fresh embryo transfer; NFTET, natural cycle frozenthawed embryo transfer; HFTET, hormone-replacement cycle frozen-thawed embryo transfer. ${ }^{*} P$ value was calculated by the log-rank test or linear regression analysis when appropriate

\begin{tabular}{|c|c|c|c|c|c|c|}
\hline Confounders & $\begin{array}{c}\text { IVST } \\
(P \text { value })\end{array}$ & $\begin{array}{l}\text { LVPWT } \\
(P \text { value })\end{array}$ & $\begin{array}{c}\text { LVMI } \\
(P \text { value })\end{array}$ & $\begin{array}{c}\text { LVRI } \\
(P \text { value })\end{array}$ & $\begin{array}{l}\text { Mitral A } \\
(P \text { value })\end{array}$ & $\begin{array}{l}\text { Mitral } \mathrm{E}^{\prime} \\
(P \text { value })\end{array}$ \\
\hline Age & $<0.001$ & $<0.001$ & 0.602 & 0.003 & $<0.001$ & $<0.001$ \\
\hline Gender & 0.555 & 0.497 & 0.277 & 0.022 & 0.983 & 0.260 \\
\hline Heart rate & 0.075 & 0.015 & 0.016 & 0.399 & $<0.001$ & 0.025 \\
\hline Body mass index & 0.089 & 0.486 & 0.024 & 0.070 & 0.336 & 0.056 \\
\hline Body surface area & $<0.001$ & $<0.001$ & 0.814 & 0.030 & $<0.001$ & $<0.001$ \\
\hline $\begin{array}{l}\text { Pregnancy } \\
\text { (Singleton/ Twin) }\end{array}$ & 0.356 & 0.361 & 0.240 & 0.314 & 0.050 & 0.142 \\
\hline Delivery & 0.252 & 0.645 & 0.261 & 0.194 & 0.005 & 0.019 \\
\hline $\begin{array}{l}\text { Neonatal outcome } \\
\text { (Normal/ Adverse) }\end{array}$ & $<0.001$ & $<0.001$ & $<0.001$ & $<0.001$ & 0.030 & 0.302 \\
\hline Apgar score & & & & & & \\
\hline At $1 \mathrm{~min}$ & 0.757 & 0.173 & 0.248 & 0.280 & 0.361 & 0.642 \\
\hline At $5 \mathrm{~min}$ & 0.149 & 0.718 & 0.121 & 0.953 & 0.138 & 0.772 \\
\hline $\begin{array}{l}\text { Amniotic fluid } \\
\text { (Clarity/ Turbidity I/ II/ III) }\end{array}$ & 0.746 & 0.964 & 0.608 & 0.666 & 0.012 & 0.513 \\
\hline Birth weight & 0.006 & 0.013 & 0.001 & 0.043 & 0.242 & 0.864 \\
\hline Gestational age & 0.862 & 0.424 & 0.072 & 0.655 & 0.022 & 0.015 \\
\hline $\begin{array}{l}\text { Etiological infertility cause } \\
\text { (Normal/ Primary/ Secondary) }\end{array}$ & 0.004 & $<0.001$ & $<0.001$ & 0.009 & 0.014 & 0.027 \\
\hline $\begin{array}{l}\text { Parental infertility cause } \\
\text { (Normal/ Female/ Male/ } \\
\text { Female+male/ Unexplained/) }\end{array}$ & 0.011 & $<0.001$ & 0.002 & 0.007 & 0.047 & 0.058 \\
\hline $\begin{array}{l}\text { Reproductive technique } \\
(\mathrm{NC} / \mathrm{IVF} / \mathrm{ICSI} / \mathrm{IVF}+\mathrm{ICSI} / \mathrm{AI})\end{array}$ & 0.012 & $<0.001$ & 0.001 & 0.013 & 0.031 & 0.072 \\
\hline $\begin{array}{l}\text { Sperm acquisition mode } \\
\text { (IES/ EES/ SES) }\end{array}$ & 0.003 & $<0.001$ & $<0.001$ & 0.007 & 0.003 & 0.020 \\
\hline $\begin{array}{l}\text { Sperm origin } \\
\text { (Husband/ Donor) }\end{array}$ & 0.629 & 0.732 & 0.122 & 0.807 & 0.176 & 0.852 \\
\hline $\begin{array}{l}\text { Ovulation control } \\
(\mathrm{NC} / \mathrm{COS} / \mathrm{MS} / \mathrm{OI}+\mathrm{COS})\end{array}$ & $<0.001$ & $<0.001$ & 0.011 & $<0.001$ & 0.001 & 0.054 \\
\hline $\begin{array}{l}\text { Embryo transfer modality } \\
\text { (NC/FET/NFTET/HFTET) }\end{array}$ & 0.004 & $<0.001$ & $<0.001$ & 0.007 & 0.028 & 0.077 \\
\hline $\begin{array}{l}\text { Embryo transfer stage } \\
\text { (NC/ Early cleavage/ Blastocyst) }\end{array}$ & 0.002 & $<0.001$ & $<0.001$ & 0.003 & 0.016 & 0.098 \\
\hline Embryos transferred number & 0.006 & $<0.001$ & $<0.001$ & 0.012 & $<0.001$ & 0.037 \\
\hline
\end{tabular}

In addition to the increased IVST, LVPWT and RWT, the significantly increasing tendency of ART children toward both LVMI and LVRI compared with controls suggested the possibility of LV remodeling. In line with previous clinical [20] and experimental research [32] demonstrating patterns of remodeling in ART subjects, our findings provide additional evidence for the extent of remodeling in ART children. From an etiological perspective, increasingly hypertrophic ventricles accompanied by a reduction in longitudinal function usually develop in response to hemodynamic overload in either physiological or pathological conditions [33]. However, the results revealed an insignificant elevation of systolic and diastolic blood pressures, alterations in aortocoronary morphometry, and dilation in the left chambers among the ART group compared with the controls, which differs from previous reports indicating the potential dysfunction of vascular structures and function in ART children [17-20]. Considering the unlikely attribution of cardiac remodeling to pressure and volume overload, further Cox analysis suggested the independent association of perinatal outcomes (i.e., delivery, birth weight, and neonatal complications) and the ART procedure itself (i.e., hormonal stimulation and stage and number of embryos transferred) with $\mathrm{LV}$ remodeling in addition to the anthropometrics of participants. Given that subsequent changes in remodeling from childhood to adolescence and adulthood may progress to ventricular hypertrophy, depressed systolic function and overt heart failure [34, 35], it is of great value to distinguish those ART children at high risk of cardiac remodeling and identify 
Zhou et al.: Cardiac Development in Assisted Reproductive Techniques

Table 5. Cox proportional hazard analysis of independent predictors associated with cardiac developmental health. ART indicates pregnancy conceived by assisted reproductive technologies; IVST, interventricular septum thickness; LVPWT, left ventricular posterior wall thickness; LVMI, left ventricular mass index; LVRI, left ventricular remodeling index; A, ventricular inflow during atrial contraction; E', annular peak velocity in early diastole; NC, natural conception; IVF, in-vitro fertilization; ICSI, intracytoplasmic sperm injection; AI, artificial insemination; COS, controlled ovarian simulation; MS, mini-

\begin{tabular}{|c|c|c|c|c|c|c|}
\hline Confounders & $\begin{array}{c}\text { IVST } \\
(P+\text { value })\end{array}$ & $\begin{array}{c}\text { LVPWT } \\
(P+\text { value })\end{array}$ & $\begin{array}{c}\text { LVMI } \\
(P+\text { value })\end{array}$ & $\begin{array}{c}\text { LVRI } \\
(P+\text { value })\end{array}$ & $\begin{array}{c}\text { Mitral A } \\
(P+\text { value })\end{array}$ & $\begin{array}{l}\text { Mitral } E^{\prime} \\
(P+\text { value })\end{array}$ \\
\hline Age & 0.790 & $<0.001$ & NA & 0.182 & $<0.001$ & $<0.001$ \\
\hline Heart rate & 0.056 & 0.029 & 0.127 & NA & 0.083 & 0.413 \\
\hline Body mass index & $<0.001$ & NA & 0.010 & 0.050 & NA & 0.423 \\
\hline Body surface area & $<0.001$ & 0.804 & NA & 0.625 & 0.271 & 0.973 \\
\hline $\begin{array}{l}\text { Delivery } \\
\text { (Cesarean/Spontaneous) }\end{array}$ & NA & NA & NA & NA & $<0.001$ & 0.205 \\
\hline $\begin{array}{l}\text { Neonatal outcome } \\
\text { (Normal/ Adverse) }\end{array}$ & $<0.001$ & $<0.001$ & $<0.001$ & $<0.001$ & 0.150 & $\mathrm{NA}$ \\
\hline $\begin{array}{l}\text { Amniotic fluid } \\
\text { (Clarity/ Turbidity I/ II/ III) }\end{array}$ & NA & NA & NA & $\mathrm{NA}$ & 0.063 & $\mathrm{NA}$ \\
\hline Birth weight, g & 0.056 & 0.342 & 0.006 & 0.099 & NA & NA \\
\hline Gestational age at delivery & NA & NA & 0.776 & NA & 0.081 & 0.555 \\
\hline $\begin{array}{l}\text { Etiological infertility cause } \\
\text { (Normal/ Primary/ Secondary) }\end{array}$ & 0.470 & 0.439 & 0.651 & 0.679 & 0.765 & 0.649 \\
\hline $\begin{array}{l}\text { Parental infertility cause } \\
\text { (Normal/ Female/ Male/ } \\
\text { Female+male/ Unexplained/) }\end{array}$ & 0.218 & 0.112 & 0.417 & 0.218 & 0.541 & 0.616 \\
\hline $\begin{array}{l}\text { Reproductive technique } \\
(\mathrm{NC} / \mathrm{IVF} / \mathrm{ICSI} / \mathrm{IVF}+\mathrm{ICSI} / \mathrm{AI})\end{array}$ & 0.998 & 0.911 & 0.937 & 0.450 & 0.521 & 0.392 \\
\hline $\begin{array}{l}\text { Sperm acquisition } \\
\text { (IES/ EES/ SES) }\end{array}$ & 0.834 & 0.791 & 0.790 & 0.568 & 0.082 & 0.845 \\
\hline $\begin{array}{l}\text { Hormonal stimulation } \\
\text { (NC/COS/MS/OI+COS) }\end{array}$ & 0.091 & 0.046 & 0.202 & 0.001 & 0.362 & 0.790 \\
\hline $\begin{array}{l}\text { Embryo transfer modality } \\
\text { (NC/FET/NFTET/HFTET) }\end{array}$ & 0.883 & 0.981 & 0.955 & 0.411 & 0.968 & 0.586 \\
\hline $\begin{array}{l}\text { Embryo transfer stage } \\
\text { (NC/ Early cleavage/ Blastocyst) }\end{array}$ & 0.001 & 0.007 & $<0.001$ & 0.259 & 0.987 & 0.602 \\
\hline Embryos transferred number & 0.947 & 0.932 & 0.548 & 0.282 & $<0.001$ & 0.035 \\
\hline
\end{tabular}

stimulation; OI, ovulation induction; FET, fresh embryo transfer; NFTET, natural cycle frozen-thawed embryo transfer; HFTET, hormone-replacement cycle frozen-thawed embryo transfer; NA, not applicable. $\dagger$ indicates Cox proportional hazards analysis by method of forward likelihood ratio (LR)

risk factors leading to the progression of remodeling at the early stages, when the changes remain reversible and systolic function is preserved [36, 37]. It is also important to evaluate the cardiac geometric morphology among infants and children, which contributes to possible early interventions for the at-risk population.

With regard to cardiac function, the reduction in mitral $\mathrm{A}$ and mitral $\mathrm{E}^{\prime}$, as well as an increase in mitral E/A and mitral E/E' ratios, suggested signs of cardiac diastolic dysfunction in ART children compared with controls, while no evidence supported the direct impact of ART on the changes in systolic function during childhood. In contrast to the latest study [20], in which ART children had signs of both cardiac systolic and diastolic dysfunctions, our findings may be attributed to the dominance of diastolic function during childhood and a higher susceptibility of diastolic function to contributing confounders compared with systolic function $[38,39]$. Among the ART children, the impaired relaxation could be explained by a decrease in ventricular compliance partly due to LV remodeling. Furthermore, Cox multivariate analysis suggested that age, delivery and the number of embryos transferred are independently associated with the risk of diastolic dysfunction with ART. Numerous clinical studies and experimental models have demonstrated that diastolic dysfunction is involved in the increasing risk and frequency of deterioration of systolic dysfunction, especially in subjects with LV remodeling with had preserved LVEF [40]. Consequently, appropriate recognition of the presence of preclinical diastolic dysfunction and early identification of 
the risk factors of diastolic dysfunction in ART children relative to controls is advisable to prevent further progression to systolic dysfunction.

The mechanisms dominating cardiac remodeling and diastolic dysfunction in ART children require further elaboration, despite their extensive discussion in the literature. Considerable evidence suggests a possible association between parental predisposing factors and epigenetic alterations secondary to ART procedures and postnatal environmental confounders with such changes [41,42]. Not taking into consideration the causes of parental infertility in present study, it is likely that the other parental covariates irrelevant to infertility mediate and affect the emergence, development and progression of remodeling and dysfunction [43]. Our findings from Cox analysis approximately reproduce these consequences and support the development and presence of remodeling and diastolic dysfunction from early life [44]. Despite the gradual certainty of the potential involvement of epigenetic changes in cardiovascular regulation among ART pregnancies, it remains challenging to ascertain the causative association of incremental risks for epigenetic disorders and ART exposure due to the complexity of ART procedures and the instability of epigenetic disorders $[45,46]$. Although we determined the existence of potential confounders affecting cardiac developmental health, it can hardly be denied that postnatal environmental factors also likely affect the postnatal development of the heart [47]. Consequently, the potential impact of the postnatal environment by driving progressive changes in cardiovascular development during aging requires further study.

Inevitably, our study has several limitations and considerations. Because of the dramatic alteration of cardiovascular development in cardiac geometric morphology and hemodynamics during childhood, as well as the scarcity of recognized standards designed for children, our findings should be interpreted cautiously in this context. Cases and controls were considered by their age when initially recruited; however, the uncontrollable differences produced by ART (e.g., the tendency towards twins in pregnancy) make it more difficult to examine the ART signatures compared with controls, even after adjustment for other potential confounders. In addition, in our study, the children's blood pressures were assessed over a wide age range, from 2 to 6 years old, and this limitation may provide insufficient power to detect a potentially significant change in blood pressure in young ART children, which may contribute to the early hypertrophy phenotype occurring at 2-6 years of age in ART children [20]. Considering the focus of our present pilot study on left cardiac geometric morphology and function that limits the generalizability of our findings, the global cardiac characteristics and other potential confounders not considered in the design but likely affecting the final results deserve further attention.

\section{Conclusions}

In summary, our study supports the potential association between ART exposure and ART derived risk factors with cardiac remolding and diastolic dysfunction. Further Cox analysis suggests that the anthropometrics and perinatal outcomes in addition to ART procedure are independently associated with the changes in abnormal cardiac development among ART children compared with controls. On the basis of prophylaxis, our findings also account for the possibility and feasibility of early identification of ART children at risk for cardiovascular abnormalities, and they provide opportunities for further interventions and the prevention of progression to enable better cardiovascular development in the relevant at-risk population of ART children [48]. However, future studies should further elucidate the underlying mechanisms of potential confounders and follow the long-term cardiac impact on ART children. 


\section{Disclosure Statement}

The authors have no conflicts of interest.

\section{Acknowledgments}

This study was supported by grants from National Basic Research Program of China (973 Programme: No. 2012CB944902 and No. 2012CB944903).

\section{References}

1

$>_{2}$

$>3$

$>4$

$>5$

$>6$

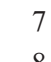

$>8$

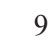

$>10$

Steptoe PC, Edwards RG: Birth after the reimplantation of a human embryo. Lancet 1978;2:366. Talaulikar VS, Arulkumaran S: Maternal, perinatal and long-term outcomes after assisted reproductive techniques (ART): implications for clinical practice. Eur J Obstet Gynecol Reprod Biol 2013;170:13-19. Boivin J, Bunting L, Collins JA, Nygren KG: International estimates of infertility prevalence and treatmentseeking: potential need and demand for infertility medical care. Human Reproduction 2007;22:1506-1512. Vulliemoz NR, McVeigh E, Kurinczuk J: In vitro fertilisation: perinatal risks and early childhood outcomes. Hum Fertil (Camb) 2012;15:62-68.

Hansen M, Bower C, Milne E, de Klerk N, Kurinczuk JJ: Assisted reproductive technologies and the risk of birth defects-a systematic review. Hum Reprod 2005;20:328-338.

Lie RT, Lyngstadaas A, Ørstavik KH, Bakketeig LS, Jacobsen G, Tanbo T: Birth defects in children conceived by ICSI compared with children conceived by other IVF-methods: a meta-analysis. Int J Epidemiol 2005;34:696-701.

Nejat EJ, Buyuk E: Reproductive technologies and the risk of birth defects. N Engl J Med 2012;367:875-876. van Montfoort AP, Hanssen LL, de Sutter P, Viville S, Geraedts JP, de Boer P: Assisted reproduction treatment and epigenetic inheritance. Hum Reprod Update 2012;18:171-197.

Cutfield WS, Hofman PL, Mitchell M, Morison IM: Could epigenetics play a role in the developmental origins of health and disease? Pediatr Res 2007;61:68R-75R.

Chen W, Srinivasan SR, Yao L, Li S, Dasmahapatra P, Fernandez C, Xu J, Berenson GS: Low birth weight is associated with higher blood pressure variability from childhood to young adulthood: the Bogalusa Heart Study. Am J Epidemiol 2012;176Suppl7:S99-S105.

Wadhwa PD, Buss C, Entringer S, Swanson JM: Developmental origins of health and disease: brief history of the approach and current focus on epigenetic mechanisms. Semin Reprod Med 2009;27:358-268.

Koukoura O, Sifakis S, Spandidos DA. DNA methylation in the human placenta and fetal growth. Mol Med Rep 2012;5:883-889.

Strömberg B, Dahlquist G, Ericson A, Finnström O, Köster M, Stjernqvist K: Neurological sequelae in children born after in-vitro fertilisation: a population-based study. Lancet 2002;359:461-465.

Eroglu A, Layman LC: Role of ART in imprinting disorders. Semin Reprod Med 2012;30:92-104.

Sandin S, Nygren KG, Iliadou A, Hultman CM, Reichenberg A: Autism and mental retardation among offspring born after in vitro fertilization. JAMA 2013;310:75-84.

Celermajer DS: Manipulating nature: might there be a cardiovascular price to pay for the miracle of assisted conception? Circulation 2012;125:1832-1834.

Ceelen M, van Weissenbruch MM, Vermeiden JP, van Leeuwen FE, Delemarre-van de Waal HA: Cardiometabolic differences in children born after in vitro fertilization: follow-up study. J Clin Endocrinol Metab 2008;93:1682-1688.

Belva F, Roelants M, De Schepper J, Roseboom TJ, Bonduelle M, Devroey P, Painter RC: Blood pressure in ICSI-conceived adolescents. Hum Reprod 2012;27:3100-3118.

Scherrer U, Rimoldi SF, Rexhaj E, Stuber T, Duplain H, Garcin S, de Marchi SF, Nicod P, Germond M, Allemann Y, Sartori C: Systemic and pulmonary vascular dysfunction in children conceived by assisted reproductive technologies. Circulation 2012;125:1890-1896. 
20 Valenzuela-Alcaraz B, Crispi F, Bijnens B, Cruz-Lemini M, Creus M, Sitges M, Bartrons J, Civico S, Balasch J, Gratacós E: Assisted reproductive technologies are associated with cardiovascular remodeling in utero that persists postnatally. Circulation 2013;128:1442-1450.

21 Smith KE, Buyalos RP: The profound impact of patient age on pregnancy outcome after early detection of fetal cardiac activity. Fertile Steril 1996;65:35-40.

-22 McIntosh GC, Olshan AF, Baird PA: Paternal age and the risk of birth defects in offspring. Epidemiology 1995;6:282-288.

23 Lai WW, Geva T, Shirali GS, Frommelt PC, Humes RA, Brook MM, Pignatelli RH, Rychik J, Task Force of the Pediatric Council of the American Society of Echocardiography, Pediatric Council of the American Society of Echocardiography: Guidelines and standards for performance of a pediatric echocardiogram: a report from the Task Force of the Pediatric Council of the American Society of Echocardiography. J Am Soc Echocardiogr 2006;19:1413-1430.

24 Lopez L, Colan SD, Frommelt PC, Ensing GJ, Kendall K, Younoszai AK, Lai WW, Geva T: Recommendations for quantification methods during the performance of a pediatric echocardiogram: a report from the Pediatric Measurements Writing Group of the American Society of Echocardiography Pediatric and Congenital Heart Disease Council. J Am Soc Echocardiogr 2010;23:465-495.

25 Lang RM, Bierig M, Devereux RB, Flachskampf FA, Foster E, Pellikka PA, Picard MH, Roman MJ, Seward J, Shanewise JS, Solomon SD, Spencer KT, Sutton MS \& Stewart WJ: Recommendations for chamber quantification: a report from the American Society of Echocardiography's Guidelines and Standards Committee and the Chamber Quantification Writing Group, developed in conjunction with the European Association of Echocardiography, a branch of the European Society of Cardiology. Journal of the American Society of Echocardiography 2005;18:1440-1446.

-26 Nagueh SF, Appleton CP, Gillebert TC, Marino PN, Oh JK, Smiseth OA, Waggoner AD, Flachskampf FA, Pellikka PA, Evangelista A: Recommendations for the evaluation of left ventricular diastolic function by echocardiography. J Am Soc Echocardiogr 2009;22:107-133.

27 Fowlkes JB, Holland CK: Mechanical bioeffects from diagnostic ultrasound: AIUM consensus statements. American Institute of Ultrasound in Medicine. J Ultrasound Med 2000;19:69-72.

28 Barnett SB, Ter Haar GR, Ziskin MC, Rott HD, Duck FA, Maeda K: International recommendations and guidelines for the safe use of diagnostic ultrasound in medicine. Ultrasound Med Biol 2000;26:355-366.

29 Devereux RB, Alonso DR, Lutas EM, Gottlieb GJ, Campo E, Sachs I, Reichek N: Echocardiographic assessment of left ventricular hypertrophy: comparison to necropsy findings. Am J Cardiol 1986;57:450458.

30 Stevenson PH: Height-Weight-Surface formula for the estimation of surface area in Chinese subjects. Chin J Physiol 1937;3:327-330.

-31 Dumesnil JG, Gaudreault G, Honos GN, Kingma JG Jr: Use of Valsalva maneuver to unmask left ventricular diastolic function abnormalities by Doppler echocardiography in patients with coronary artery disease or systemic hypertension. Am J Cardiol 1991;68:515-519.

-32 Hiendleder S, Wirtz M, Mund C, Klempt M, Reichenbach HD, Stojkovic M, Weppert M, Wenigerkind H, Elmlinger M, Lyko F, Schmitz OJ, Wolf E: Tissue-specific effects of in vitro fertilization procedures on genomic cytosine methylation levels in overgrown and normal sized bovine fetuses. Biol Reprod 2006;75:17-23.

-33 Lorell BH, Carabello BA: Left ventricular hypertrophy: pathogenesis, detection, and prognosis. Circulation 2000;102:470-479.

-34 Mimura I, Nishi H, Mise N, Mori M, Sugimoto T: Left ventricular geometry and cardiovascular mortality based on haemodialysis patient autopsy analyses. Nephrology 2010;15:549-554.

-35 Lavie CJ, Milani RV, Patel D, Artham SM,Ventura HO: Disparate effects of obesity and left ventricular geometry on mortality in 8088 elderly patients with preserved systolic function. Postgrad Med 2009;121:119-125.

-36 Verma A, Meris A, Skali H, Ghali JK, Arnold JM, Bourgoun M, Velazquez EJ, McMurray JJ, Kober L, Pfeffer MA, Califf RM, Solomon SD: Prognostic implications of left ventricular mass and geometry following myocardial infarction: the VALIANT (VALsartan In Acute myocardial iNfarcTion) Echocardiographic Study. JACC Cardiovasc Imaging 2008;1:582-591.

-37 Konstam MA, Udelson JE, Anand IS, Cohn JN: Ventricular remodeling in heart failure: a credible surrogate endpoint. J Card Fail 2003;9:350-353. 
Zhou et al.: Cardiac Development in Assisted Reproductive Techniques

-38 Chaoui R, Heling KS, Taddei F, Bollmann R. Doppler echocardiographic analysis of blood flow through the fetal aorta and pulmonary valve in the second half of pregnancy. Geburtshilfe Frauenheilkd 1995;55:20717.

-39 Mielke G, Benda N: Cardiac output and central distribution of blood flow in the human fetus. Circulation 2001;103:1662-1668.

40 Katz DH, Beussink L, Sauer AJ, Freed BH, Burke MA, Shah SJ: Prevalence, clinical characteristics, and outcomes associated with eccentric versus concentric left ventricular hypertrophy in heart failure with preserved ejection fraction. Am J Cardiol 2013;112:1158-1164.

-41 Rinaudo P, Wang E: Fetal programming and metabolic syndrome. Annu Rev Physiol 2012;74:107-130.

42 Balasch J, Gratacós E: Delayed childbearing: effects on fertility and the outcome of pregnancy. Fetal Diagn Ther 2011;29:263-273.

43 Vergouw CG, Kostelijk EH, Doejaaren E, Hompes PG, Lambalk CB, Schats R: The influence of the type of embryo culture medium on neonatal birthweight after single embryo transfer in IVF. Hum Reprod 2012;27:2619-2626.

44 Barker DJ: The origins of the developmental origins theory. J Intern Med 2007;261:412-417.

-45 Eroglu A, Layman LC: Role of ART in imprinting disorders. Semin Reprod Med 2012;30:92-104.

46 Middelburg KJ, Haadsma ML, Heineman MJ, Bos AF, Hadders-Algra M: Ovarian hyperstimulation and the in vitro fertilization procedure do not influence early neuromotor development; a history of subfertility does. Fertil Steril 2010;93:544-553.

-47 van den Hooven EH, de Jonge LL, Kiefte-de Jong JC, Raat H, Villamor E, Hofman A, Felix JF, Jaddoe VW, Moll HA, Franco OH: Infant macronutrient composition is associated with differences in cardiovascular structures and function in childhood. J Nutr 2013;143:1989-1998.

-48 Kavey RE, Allada V, Daniels SR, Hayman LL, McCrindle BW, Newburger JW, Parekh RS, Steinberger J, American Heart Association Expert Panel on Population andPrevention Science, American Heart Association Council on Cardiovascular Disease in the Young; American Heart Association Council on Epidemiology and Prevention, American Heart Association Council on Nutrition, Physical Activity and Metabolism; American Heart Association Council on High Blood Pressure Research; American Heart Association Council on Cardiovascular Nursing, American Heart Association Council on the Kidney in Heart Disease, Interdisciplinary Working Group on Quality of Care and Outcomes Research: Cardiovascular risk reduction in high-risk pediatric patients: a scientific statement from the American Heart Association Expert Panel on Population and Prevention Science; the Councils on Cardiovascular Disease in the Young, Epidemiology and Prevention, Nutrition, Physical Activity and Metabolism, High Blood Pressure Research, Cardiovascular Nursing, and the Kidney in Heart Disease; and the Interdisciplinary Working Group on Quality of Care and Outcomes Research: endorsed by the American Academy of Pediatrics. Circulation 2006;114:2710-2738. 